c) Elsevier Scientific Publishing Company, Amsterdam - Printed in The Netherlands

\title{
THE PRIMARY VASCULAR SYSTEM OF CALLIXYLON
}

\section{CHARLES B. BECK}

Department of Botany, University of Michigan, Ann Arbor, Mich. 48109 (U.S.A.)

(Received December 18, (1978)

\section{ABSTRACT}

Beck, C.B., 1979. The primary vascular system of Callixylon. Rev. Palaeobot. Palynol., 28: $103-115$.

The primary vascular system of Callixylon (main stem axes of Archaeopteris) is composed of a discontinuous cylinder of longitudinal bundles from some of which traces diverge radially in a regular, helical pattern. Tangential divisions and fusions of primary xylem strands occur in approximately equal frequency and, thus, the number of bundles in the system remains constant in the specimen studied. Following divergence, traces increase in size and become ribbed distally. The available evidence suggests that all of the traces observed in this study are branch traces. Branch bases, embedded in secondary xylem, have the anatomical characteristics of penultimate axes of lateral branch systems of Archaeopteris. It is suggested that some regions of main axes of Archaeopteris might have borne lateral branch systems only, lacking entirely simple leaves. Lateral branch systems, therefore, might have been more similar to compound leaves than previously supposed.

\section{INTRODUCTION}

During the past decade Archaeopteris and related progymnosperms have provided a focus for considerations of the origin of seed plants. Although Archaeopteris is one of the most completely studied Devonian plants, there are several areas of considerable interest about which we have incomplete information, prominent among which is the architecture of the primary vascular system of main axes (Callixylon). A detailed and comprehensive knowledge of the morphology of the primary vascular system of Callixylon is essential in order to understand better the significance of this plant in the origin of seed plants as well as in the evolution of the eustele and the compound leaf.

Studies by Carluccio et al. (1966) and Beck (1971) provided some detailed information on the anatomy and morphology of lateral branch systems of Archaeopteris, and Scheckler (1978) has provided additional information showing, particularly, variation in the patterns of primary vasculature in the lateral branch systems. Although Arnold (1930) provided some basic information on the primary vascular system of Callixylon, main axes of Archaeopteris, it has not been investigated in detail. 
Beck (1970) considering the origin of the eustele, suggested on the basis of preliminary studies that the "reparatory strand" of Callixylon might be comparable to the accessory bundle of Calamopitys foerstei. In C. foerstei the axial bundle divides tangentially to form the accessory bundle/trace complex. Following radial separation of the trace from the accessory bundle, the accessory bundle simply terminates at a higher level. To maintain an approximately constant number of vascular bundles in such a vascular system the accessory bundles must either terminate (i.e., disappear from the system) or fuse with an adjacent vascular bundle as in some calamopityans (Beck, 1970; Galtier, 1973) and some specimens of Lyginopteris (BlancLouvel, 1966). We do not know which, or if either, of these conditions characterize Callixylon.

This study was undertaken in an effort to answer some of the questions surrounding the nature of the primary vascular system of Callixylon.

The material utilized consists of a specimen of Callixylon brownii collected from the Sanderson formation (Tournaisian) of the New Albany shale near Boston, Kentucky, and sections of Callixylon, primarily C. zalesskyi, prepared by Professor C.A. Arnold from specimens collected from the Genundewa limestone (Famennian) in the Finger Lakes district of western New York. Material of $C$. brownii is on file under number 124 in the paleobotanical collection of the Department of Botany, University of Michigan, Ann Arbor, Michigan, U.S.A. Three sections numbered 11074, nine numbered 11075, and one numbered CB-14 (Callixylon zalesskyi), one numbered 11077 (Callixylon erianum) and one numbered 11081 (Callixylon sp.) are on file in the Museum of Paleontology, University of Michigan, Ann Arbor, Michigan, U.S.A. Serial transverse sections of $C$. brownii were analyzed and plotted in one plane yielding the diagram of the primary vascular pattern illustrated in Fig.4.

\section{DESCRIPTION OF THE SYSTEM}

The primary vascular system of Callixylon consists of a discontinuous cylinder of vascular bundles, represented in the material studied by mesarch primary xylem strands only. The number of clearly recognizable bundles varies among the different specimens studied from about 15 to over 40 . Within the system, vascular bundles may divide and fuse tangentially, and traces diverge radially from certain bundles (Figs.1-4).

The specimen of Callixylon brownii was analyzed in great detail. Its primary vascular system consists of about 40 bundles (Figs.2-4) exclusive of traces which diverge radially in a regular helical pattern (Fig.4). Traces actually observed are indicated by black triangles at the presumed level of entry into lateral appendages. Traces 21, 20,19 and 18 may be observed in various stages of divergence in the transverse sections illustrated in Figs.2 and 3 . The approximate levels of these sections in the axis are indicated in Fig.4 to indicate the relationship between these traces in the sections and their positions in the diagram in Fig.4. Unshaded triangles represent traces 


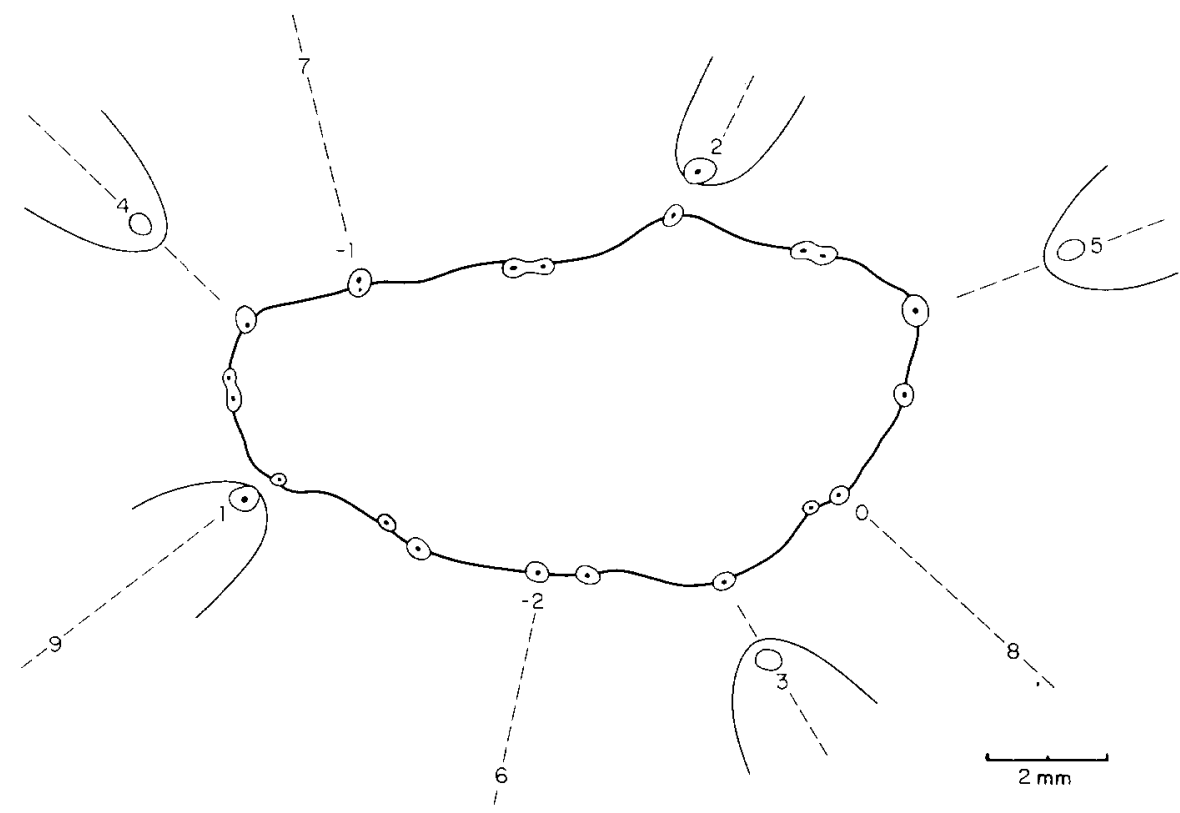

Fig.1. Camera lucida drawing of a transverse view representing the primary vascular system and traces of Callixylon zalesskyi. Black dots represent protoxylem strands. Traces are numbered in their order of development along the clockwise ontogenetic spiral. Dashed lines, three of which are hypothetical, represent orthostichies. Slide \# 11074 (CB-0).

deduced, on the basis of the observed pattern, to occur in the positions indicated. Traces are numbered in order of development along the ontogenetic spiral. Series of right- and left-handed parastiches are apparent. There are 13 orthostichies with consecutive traces in each orthostichy differing numerically by 13 (e.g., 10 and $23 ; 11$ and 24 ). Fifteen primary xylem strands, on the average, and three orthostichies intervene between the divergence of consecutive traces along the ontogenetic spiral (Fig.4).

Both division and fusion of bundles occur tangentially. Note, for example, that between the levels of sections 124-1 (Figs.2, 4) and 124-3 (Figs.3, 4) bundles 11 and 12 have each divided, resulting in four bundles $(11 \mathrm{a}, \mathrm{b}$; $12 \mathrm{a}, \mathrm{b})$. A fusion is illustrated by bundles 16 and 17 , separate in section 124-1 (Figs.2, 4) and joined in sections 124-3 (Figs.3, 4).

No pattern of tangential division and fusion of bundles is apparent. Furthermore, there is little or no evidence of division or fusion of bundles in that part of the vascular system illustrated on the right side of Fig.4. Both the absence of a pattern and the infrequency of division and fusion in part of the system are probably related directly to poor preservation in one part of the specimen and/or the inability to identify with certainty very small primary xylem strands in the system.

In well-preserved parts of specimen 124 the approximately 40 primary xylem strands illustrated in Figs.2-4 are clear (Plate I, 1) as are the strands 

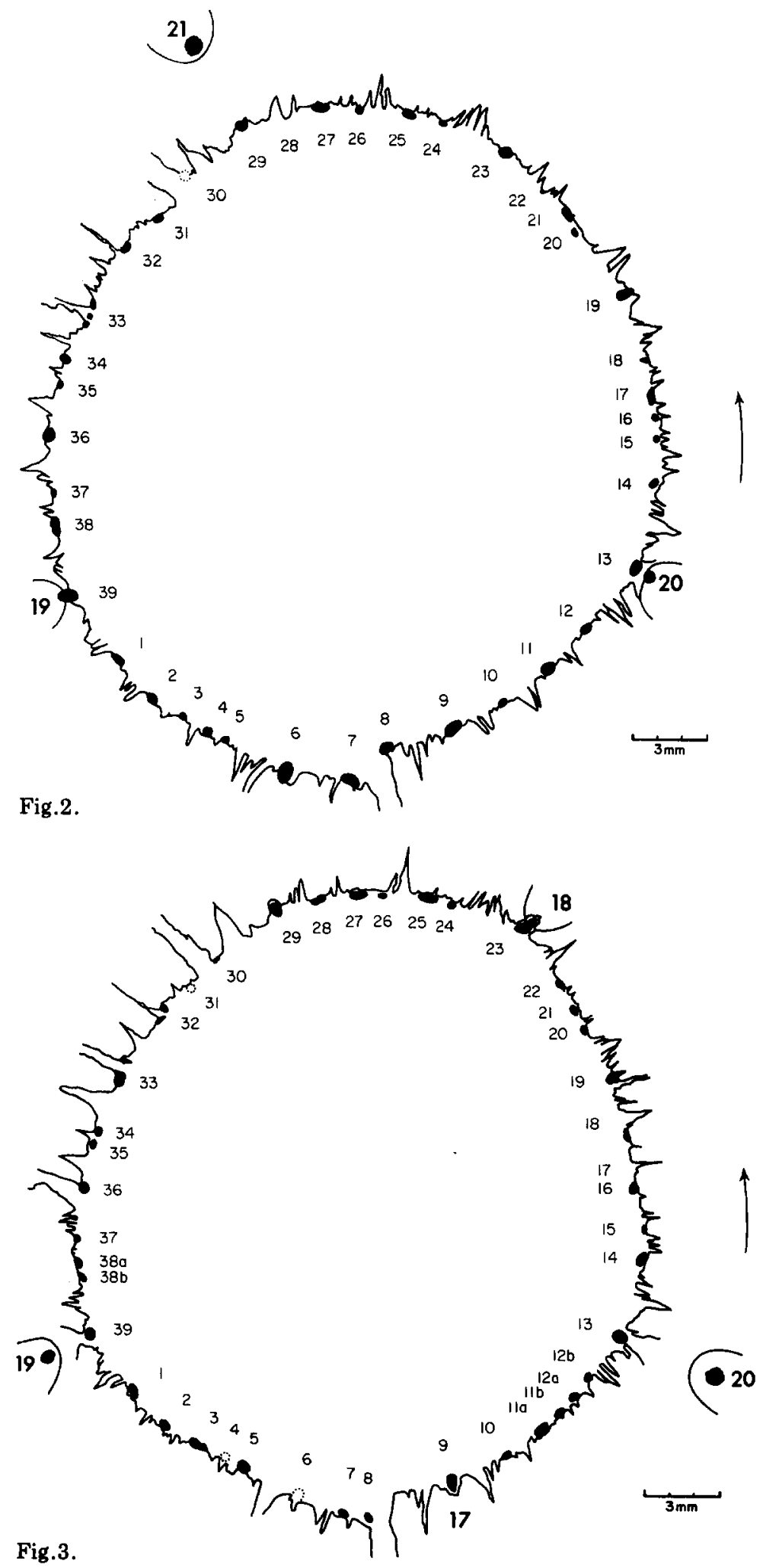


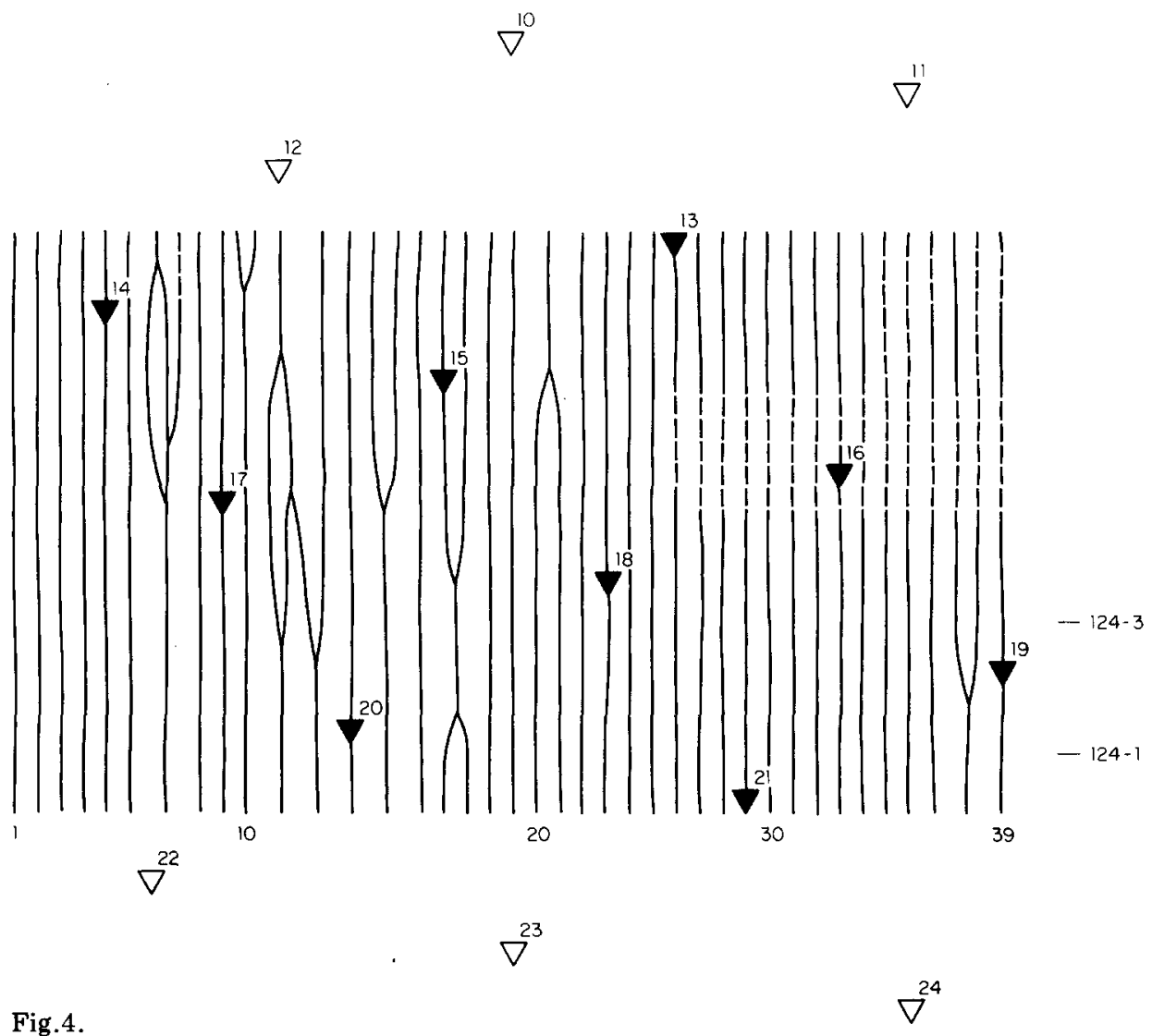

Fig.2. Camera lucida drawing of a transverse view representing the primary vascular system (black) and traces (large numbers) of Callixylon brownii. Bundle numbers correspond to those in Fig.4. The arrow indicates the direction of the ontogenetic spiral. Slide \# 124-1.

Fig.3. Camera lucida drawing of a transverse view representing the primary vascular system (black) and traces (large numbers) of Callixylon brownii. Bundle numbers correspond to those in Fig.4. The arrow indicates the direction of the ontogenetic spiral. Slide \#124-3.

Fig.4. Diagram representing the primary vascular system of Callixylon brownii as if spread out in one plane. Traces observed are indicated by black triangles; those predicted, by unshaded triangles. Traces are numbered in order of development along the ontogenetic spiral. Dashed lines represent regions where the continuity of the bundles was broken by poor preservation. The position in the system of sections 124-1 and 124-3 (represented by Figs.2, 3) are indicated to the right.

of similar size in other specimens (Plate I, 2). A matter of great significance, however, is the possible presence of additional small primary xylem strands (indicated by arrows in Plate I, 1,2) between the more conspicuous ones. If these are, indeed, representative of vascular bundles as I believe they are, then the drawings and diagrams in this paper (Figs.1-4) are incomplete. It is, 


\section{PLATE I}
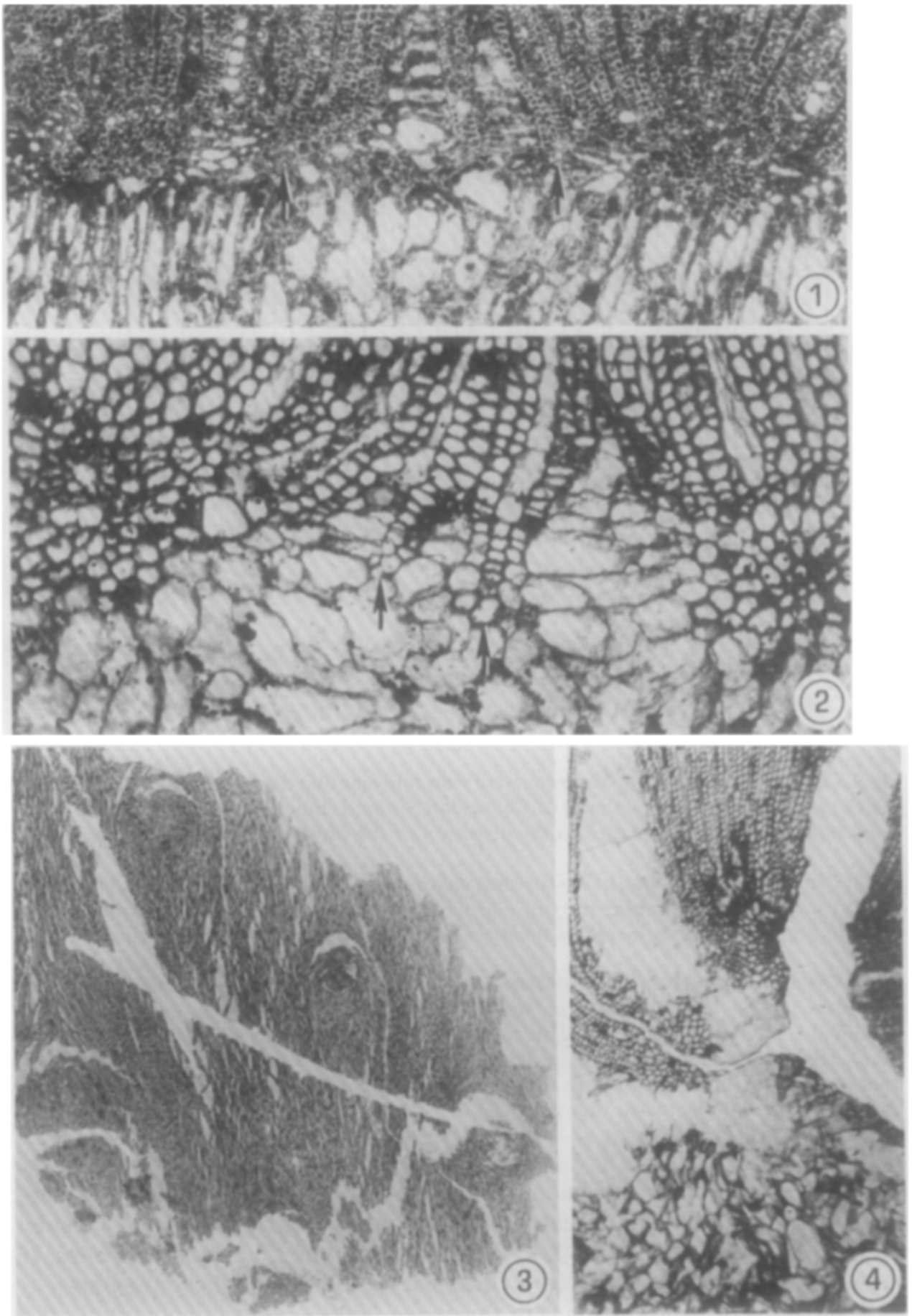
therefore, very possible that a complete representation of the primary vascular system of Callixylon will be possible only upon discovery of either a superbly preserved segment of an axis or a shoot tip with little or no secondary tissues.

A second primary vascular system considered in some detail for comparative purposes is that of a specimen of Callixylon zalesskyi (Fig.1). In contrast to that of the specimen of $C$. brownii (Figs.2-4), the system consists of only about fifteen vascular bundles (exclusive of diverging traces). The presence of tangentially elongate primary xylem bundles containing two protoxylem strands (Fig.1) and pairs of closely adjacent bundles (Fig.1) suggest that in this specimen, as in C. brownii, division and fusion of vascular bundles occurred. Five traces are apparent (numbered 1 through 5) showing five stages of divergence. On the basis of the available material, it is not possible to determine with certainty the phyllotactic fraction, but it is either $2 / 5$ or $3 / 8$. Fig. 1 has been drawn as if the phyllotaxy were $3 / 8$ and there were eight orthostichies, indicated by the dashed lines. This conclusion is based on the fact that, on the average, five bundles intervene between successive traces in the ontogenetic spiral (Fig.1). On this basis therefore, trace number 6 would have diverged in the approximate position indicated, with five bundles separating the orthostichy along which trace number 5 lies and the postulated orthostichy along which lies trace number 6 . On the other hand, the three pairs of closely adjacent bundles between the two orthostichies along which traces number 5 and 1 lie might have divided distal to the point of divergence of trace number 6 . If so, trace number 6 would probably lie along the same orthostichy as trace number 1 and the phyllotaxy would be $2 / 5$.

\section{NATURE OF THE TRACES}

At the level of separation from the stelar bundle, all traces observed are approximately the same size, or slightly larger than the stelar bundles (Figs.1-3; Plate I, 4; Plate II, 1). In average transverse dimension they measure $430 \mu \mathrm{m}$. With increasing distance from their points of divergence traces increase in size (Plate II, 1, 2; Fig.1), and become ribbed (Plate II, 2). In the bases of lateral appendages embedded in the secondary wood of Callixylon, the primary vascular system, directly continuous with such traces, is more conspicuously ribbed (Plate II, 3,4 ). In addition, it may enclose a pith and be

\section{PLATE I}

1. Callixylon brownii. Transverse section with arrows indicating probable small primary xylem strands between two more conspicous strands. Slide \# 124-1. $\times 36$.

2. Callixylon zalesskyi. Transverse section with arrows indicating probable small primary xylem strands between two more conspicuous strands. Slide \# CB-14. $\times 92$.

3. Callixylon zalesskyi. Tangential section showing five traces embedded in secondary xylem. Slide \# 11075 (CB-6). $\times 5$.

4. Callixylon zalesskyi. Transverse section showing primary xylem strand of a trace (upper strand) and the stelar strand from which it diverged. Slide \# 11074 (CB-0). $\times 32$. 


\section{PLATE II}

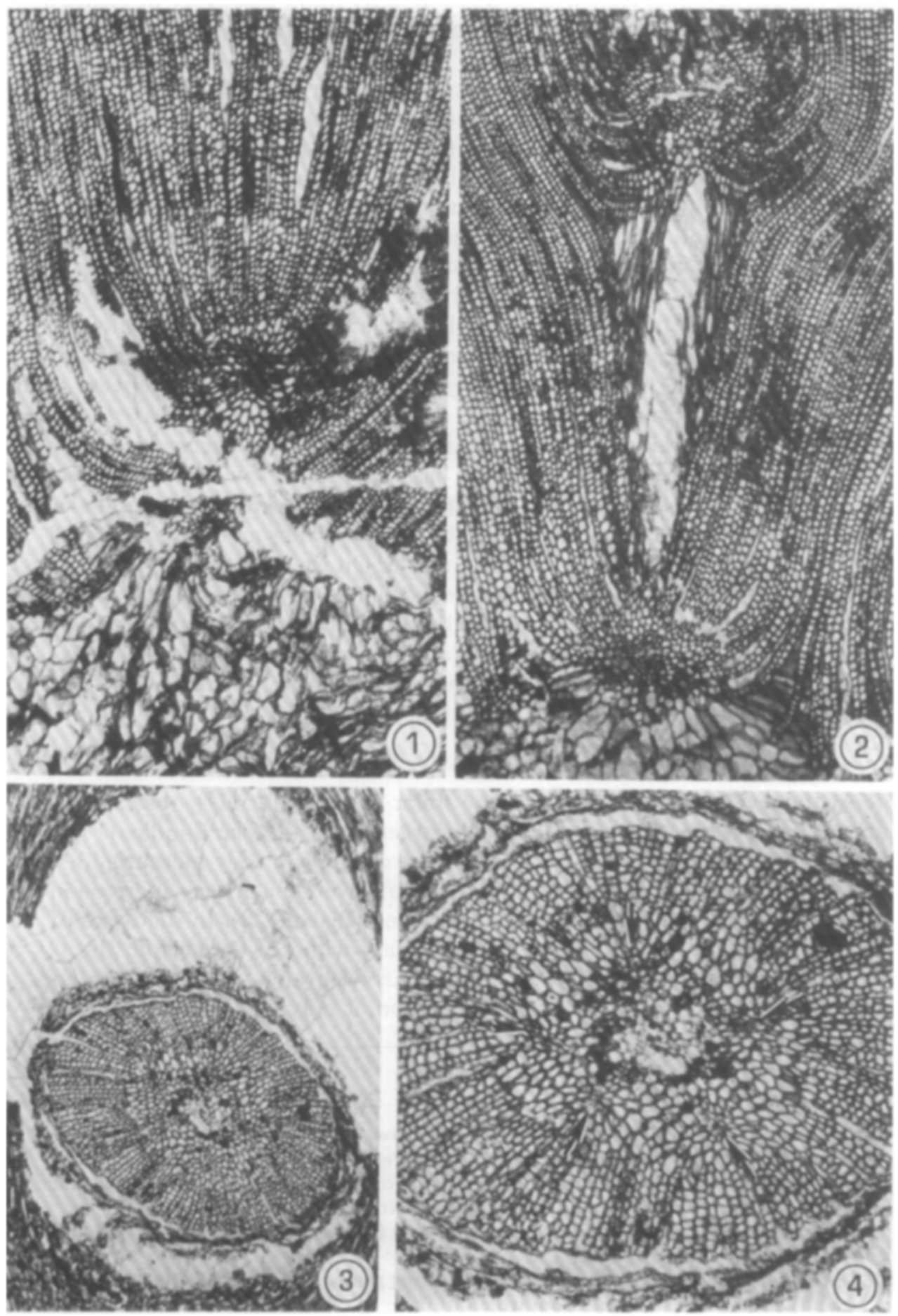


enclosed by secondary xylem produced by the cambium of the lateral appendage (Plate II, 3, 4).

The vascular system of the embedded appendage illustrated in Plate II, 3,4 is identical with that of the main axes of the plagiotropic lateral branch systems of Archaeopteris as described by Carluccio et al. (1966), Beck (1971), and Scheckler (1978). It is characterized by a cylinder of metaxylem tracheids containing five internal protoxylem strands. These occur in positions opposite ribs of metaxylem (Plate II, 4).

The abundance of embedded branch bases and/or large, ribbed traces with associated secondary xylem in the material studied has led to the question: Are all of the traces observed branch traces? On the basis of our general knowledge of Archaeopteris one might expect to find both leaf and branch traces in main axes (Callixylon). Beck, for example, described both leaves and lateral branches on an axis of Callixylon (1960), as well as on the main axis of Eddya (1967), a possible young sporophyte of Archaeopteris. And it is well known that the lateral branch systems (Archaeopteris) borne on Callixylon are characterized by both helically arranged leaves as well as ultimate branches (Carluccio et al., 1966; Beck, 1971). Nevertheless, a most careful search in the axes of Callixylon in this study has failed to provide any evidence of traces like those of the leaf traces in lateral branch systems. Indeed, the evidence seems to suggest instead that all of the traces observed and illustrated are branch traces. All of the traces that could be followed for any distance longitudinally increase in size distally and become ribbed. Not one trace has been observed to elongate tangentially and to divide as do the leaf traces of lateral branch systems (Beck, 1971). In tangential sections through secondary wood, consecutive traces and/or the bases of embedded branches along the same parastichies are essentially identical in size. Furthermore, all in which diagnostic anatomical features can be observed have the characteristics of branch traces as previously described herein or lateral branch vasculature. The average diameter of these traces at the level of separation from the stelar bundles is $430 \mu \mathrm{m}$, whereas the average diameter of leaf traces in Archaeopteris macilenta is only $185 \mu \mathrm{m}$ (Beck, 1971).

On the basis of this evidence, one can conclude (1) that some of the traces observed are branch traces, (2) all other traces observed are similar to branch traces to the extent that they can be studied, and (3) no traces have been

\section{PLATE II}

Transverse sections of Callixylon showing increase in size and ribbing of primary xylem strands of traces at different distances from their levels of initial separation from stelar bundles. Note also variation in size of stelar bundles.

1. Callixylon zalesskyi. Slide \# 11074 (CB-0). $\times 32$.

2. Callixylon sp. Slide \# 11081 (CB-13). $\times 32$.

Tangential sections through secondary xylem of Callixylon zalesskyi showing the base of an embedded lateral branch in transverse view.

3. Embedded branch base consisting of a cylinder of primary xylem possibly enclosing a pith and enclosed by secondary xylem. Slide \# 11075 (CB-7). $\times 25$.

4. Details of embedded branch base. Note five protoxylem strands (arrows) and ribbed nature of primary xylem. Slide \# 11075 (CB-7). $\times 48$. 
observed that resemble leaf traces of lateral branch systems in size and pattern of bifurcation. This is not to say, however, that some of the traces might not be leaf traces. If they are, however, one can only conclude that they differ from those in lateral branch systems in being 2-3 times larger and, apparently, in dividing (bifurcating) at a level more distal from their point of origin. Whereas these differences might not be unexpected in two different orders of branching, it is still perplexing, if both leaf and branch traces are present, that there are no recognizable differences between any of the wellpreserved embedded traces in the material studied. In the main axes of lateral branch systems branch and leaf traces can be distinguished on the basis of size (Beck, 1971; Scheckler, 1978), the branch traces being somewhat larger - according to Scheckler, $3-5$ times larger - than the leaf traces. No such difference is apparent in the material of Callixylon used in this study.

The anatomical evidence in the material studied seems, therefore, to support more strongly the hypothesis that all traces are branch traces. It does not, however, rule out the alternative possibility that both leaf and branch traces are represented, and that they are essentially indistinguishable from each other. Whereas evidence from external morphology might at first seem to support the latter hypothesis, when one analyzes the basis for the assumption that Callixylon axes should bear both leaves and branches, it becomes clear that the basis is not very compelling. For example, it has not been determined whether the vascular supply to leaves illustrated by Beck (1960) in association with the bases of lateral branches had their origin in the primary vascular system of the main axis (Callixylon) or from the lateral branches. Furthermore, the presence of leaves and branches in the determinate lateral branch systems does not provide an a priori basis for the occurrence of both on main axes of the plant. Finally, even if $E d d y a$ could be proven to be a young sporophyte of Archaeopteris, the occurrence of both leaves and branches on its main axis does not require a similar occurrence in all parts of an older plant. It is well known that the morphological characteristics of a sporeling or seedling may be quite different from those of the mature individual.

If, as seems probable, therefore, some main axes of Archaeopteris produced only lateral branch systems (and bore no leaves), our conception of the morphology of the plant must be modified.

\section{DISCUSSION}

Evidence supporting the morphological equivalence of leaves and ultimate branches in lateral branch systems has been previously presented (Beck, 1971). The occurrence of these morphologically different structures in the same ontogenetic spiral, a beautiful example of serial homology, has been recently corroborated by Scheckler (1978). He shows, further, that in some specimens, several ultimate branches may occur in succession along the ontogenetic spiral, indicating some variation from the generally plagiotropic organization of lateral branch systems. An ontogenetic succession of branches 
(without intervening leaves) in the lateral branch systems is entirely consistent with, and indirectly supportive of, the conclusion that one draws from this study of Callixylon: that in certain segments of axes only lateral branch systems, without intervening simple leaves, were borne. This morphology would also be consistent with the pseudomonopodial branching exhibited by the plant, the knowledge that lateral branch systems were determinate organs (Scheckler, 1978), the probability that they were functionally the photosynthetic organs and that they were shed as units (Beck, 1971).

If, indeed, major parts of the plant body bore only lateral branch systems which were homologous with simple leaves, there is good reason to reconsider the very nature of a leaf in Archaeopteris. Our conceptual bias, derived from knowledge of extant plants has led us to conclude that axes with radially symmetrical internal structure bearing laminate organs in some three-dimensional pattern are branches, the laminate organs they bear, leaves (Carluccio et al., 1966; Beck, 1971). It has, nevertheless, been suggested previously (Meeuse, 1966; Carluccio et al., 1966; Beck, 1970, 1971) that further evolutionary modification of lateral branch systems such as those of Archaeopteris might result in a compound frond, a view re-iterated recently by Doyle (1978). If, indeed, only lateral branch systems were borne in some regions of the main axes of Archaeopteris, as this study suggests, one could reasonably conclude that evolution in the direction of a compound frond might have proceeded further than has been supposed heretofore.

It is interesting and, perhaps, instructive to compare the primary vascular system of penultimate branches (i.e., the main axes of lateral branch systems) of Archaeopteris with that of larger axes (Callixylon) on which these were borne. There are similarities as well as several conspicuous (but probably insignificant) differences: (1) Primary xylem strands of penultimate axes are irregularly triangular in transverse outline whereas those of larger axes (Callixylon) are more nearly circular. (2) Primary xylem strands of penultimate axes form a continuous cylinder in the base of the axis, become separate and increase in number in intermediate positions, and decrease in number and fuse distally (Scheckler, 1978). Both tangential division and fusion of bundles characterize the axes of Callixylon studied but no pattern has yet been established. Furthermore, since the frequency of division and fusion is approximately equal, there is no significant change in the number of bundles throughout the stem segments. (3) In both penultimate and larger axes (Callixylon) of Archaeopteris (as well as in Eddya) traces diverge radially from stelar bundles.

The differences in configuration and number as well as in the variation in form of the primary vascular system, in the two different orders of branching are not surprising. Indeed, they are those that one would expect in a main axis and its determinate lateral. The radial divergence of traces probably reflects the origin of the Archaeopteris/Callixylon eustele directly from a protostele (Beck, 1970). A significant question that remains unsolved is the nature of the bundles from which, in Callixylon, the traces diverge radially. Beck (1970) compared them with the accessory strands of Calamopitys 
foerstei. More recently, they have been considered to be axial bundles ${ }^{1}$ by Rothwell (1976) and Scheckler (1978). This study, although not conclusive, seems to support the view that they are axial bundles. There is no evidence of a tangential division prior to trace divergence. Furthermore, the stelar bundles from which traces diverge continue their longitudinal courses without fusion with adjacent bundles for as long as they can be followed (Fig.4). Unfortunately, however, the stem segment studied was too short (about $4 \mathrm{~cm}$ ) to show the divergence of more than one trace from a single stelar bundle (Fig.4). Consequently, the question of the nature of the axial bundles has not been resolved.

The very real possibility that small vascular bundles in the system (very difficult to accurately map when the primary xylem strands are in contact with secondary xylem) have not been accounted for leads me to exhort caution in accepting any dogmatic view-point on this important issue. There is still much to learn. Hopefully, continuing studies in this laboratory and studies elsewhere will eventually solve the problem.

\section{ACKNOWLEDGEMENTS}

This study was supported by National Science Foundation grant BMS7514861.

I wish to acknowledge with appreciation the skillful technical contributions of Judith Sayenga and the loan of type slides of several species of Callixylon by the Museum of Paleontology, University of Michigan.

Discussions with James Doyle, for which I am grateful, have influenced my conception of Archaeopteris as a whole plant and, to some extent, the conclusions reached in this paper.

\section{REFERENCES}

Arnold, C.A., 1930. The genus Callixylon from the Upper Devonian of central and western New York. Pap. Mich. Acad. Sci., 11: 1-50.

Beck, C.B., 1960. The identity of Archaeorteris and Callixylon. Brittonia, 12: 351-368.

Beck, C.B., 1967. Eddya sullivanensis, gen. et sp. nov., a plant of gymnospermic morphology from the Upper Devonian of New York. Palaeontographica, B, 121: 1-22.

Beck, C.B., 1970. The appearance of gymnospermous structure. Bot. Rev. Camb. Philos. Soc., 45: 379-400.

Beck, C.B., 1971. On the anatomy and morphology of lateral branch systems of Archaeopteris. Am. J. Bot., 58: 758-784.

Blanc-Louvel, C., 1966. Étude anatomique comparée des tiges et des pétioles d'une ptéridosperme du Carbonifère du genre Lyginopteris Potonié. Mem. Mus. Nat. Hist. Nat. (Paris), Sér. C., 18: 1-103.

\footnotetext{
${ }^{1}$ Actually both of these authors used the term "sympodium" instead of axial bundle. I consider a sympodium to consist of an axial bundle and the traces which diverge from it (see Devadas and Beck, 1972).
} 
Carluccio, L.C., Hueber, F.M. and Banks, H.P., 1966. Archaeopteris macilenta, anatomy and morphology of its frond. Am. J. Bot., 53: 719-730.

Devadas, C. and Beck, C.B., 1972. Comparative morphology of the primary vascular systems in some species of Rosaceae and Leguminosae. Am. J. Bot., 59: 557-567.

Doyle, J.A., 1978. Fossil evidence on the evolutionary origin of tropical trees and forests. In: P.B. Tomlinson and M.A. Zimmermann (Editors), Tropical Trees as Living Systems. Cambridge University Press, in press..

Galtier, J., 1973. Remarques sur l'organisation et la signification phylogénétique de la stèle des Calamopityacées. C.R. Acad. Sci., Paris, 279: 975-978.

Meeuse, A.D.J., 1966. Fundamentals of Phytomorphology. Roland Press Co., New York, N.Y., 231 pp.

Rothwell, G., 1976. Primary vasculature and gymnosperm systematics. Rev. Palaeobot. Palynol., 22: 193-206.

Scheckler, S.E., 1978. Ontogeny of progymnosperms. II. Shoots of Upper Devonian Archaeopteridales. Can. J. Bot., 56: 3136-3170. 